\title{
Utilização de simulador de chuvas para determinação do valor CN e abstração inicial na cultura do café em ambiente de cerrado brasileiro
}

\author{
Use of rain simulator for determining $C N$ value and initial \\ abstraction in coffee culture in a brazilian savana environment
}

\author{
Fábio Carvalho, Instituto Federal de Goiás, Brasil, carvalhofabiogeo@gmail.com \\ (1) https://orcid.org/0000-0001-8656-1607. \\ Jefferson Gomes Confessor, Universidade Federal de Uberlândia, Brasil, jgconfessor01@gmail.com \\ (1) https://orcid.org/0000-0003-2337-4884
}

Sílvio Carlos Rodrigues, Universidade Federal de Uberlândia, Brasil, silgel@ufu.br

(1) https://orcid.org/0000-0002-5376-1773

\begin{abstract}
Resumo: O conhecimento do funcionamento hidrológico de uma bacia hidrográfica permite adotar medidas de planejamento ambiental de forma a garantir a perenidade dos recursos naturais ali inseridos. A adoção de modelos que visam expor as dinâmicas de funcionamento de fluxos de bacias se mostram de grande interesse, como o Método SCS-CN desenvolvido pelo NRCS (Natural Research Conservation Service - USDA - Departamento de Agricultura dos EUA). Entretanto, esse modelo foi elaborado sob condições edafoclimáticas distintas do território brasileiro, carecendo a calibração dos índices sob as condições ambientais específicas de cada local. O objetivo deste trabalho consiste em apresentar uma metodologia para determinar os parâmetros do Método SCS-CN, abstração inicial, escoamento superficial e os respectivos valores CN (valores Curve Number) para a cultura de café Arábica, inserida em ambiente de cerrado, por meio do uso de um simulador de chuvas em dois períodos pré-definidos (primavera-verão e outono-inverno). Os índices de abstração inicial do simulador de chuva ( $\lambda$ si) foram menores do que $\lambda=0,2$ e variaram entre as simulações de 0,03 a 0,14 observando a interferência do volume de precipitação no índice de abstração inicial. $O$ escoamento superficial esteve entre $0,18 \mathrm{~mm}$ a $6,26 \mathrm{~mm}$, apresentando variações no volume de escoamento entre as calhas. Em síntese, observa-se um aumento do volume de escoamento superficial da primeira simulação em relação à segunda simulação, não alterando significativamente os valores CNsi.
\end{abstract}

Palavras-chave: Escoamento superficial; Bacia hidrográfica; Hidrogeomorfologia; Dinâmicas superficiais.

\begin{abstract}
The knowledge of the hydrological functioning of a hydrographic basin allows the adoption of measures of environmental planning in order to guarantee the permanence of the natural resources inserted there. The adoption of models that aim to expose the dynamics of the operation of basin flows are of great interest, such as the SCS-CN Method developed by the NRCS (Natural Research Conservation Service - USDA - US Department of Agriculture). However, this model was elaborated under edaphoclimatic conditions distinct from the Brazilian territory, requiring the calibration of the indexes under the specific environmental conditions of each location. This work aimed to present a methodology to determine the parameters of the SCS-CN Method, the initial abstraction, the runoff and the respective $\mathrm{CN}$ values for the Arabica coffee culture, inserted in the cerrado environment, through the use of a rain simulator in two predefined periods (spring-summer and autumn-winter). The initial abstraction indexes of the rain simulator $(\lambda s i)$ were lower than $\lambda=0.2$ and varied between the simulations from 0.03 to 0.14 , observing the interference of the precipitation volume in the initial abstraction index. The surface runoff ranged from $0.18 \mathrm{~mm}$ to $6.26 \mathrm{~mm}$, showing a great variation in the runoff volume between the gutters. In summary, there is an increase in the runoff volume of the first simulation in relation to the second one without significantly altering the CNsi values.
\end{abstract}

Key words: Surface runoff; Hydrographic basin; Hydrogeomorphology; Surface dynamics. 


\section{Introdução}

As bacias hidrográficas são utilizadas em estudos geográficos que subsidiam estratégias de planejamento territorial. Os diversos usos e ocupações da terra presentes em uma área alteram as configurações naturais do sistema hidrológico, podendo provocar inundações, erosões e/ou deslizamentos, afetando todo o ecossistema (Silveira, 2009; Tucci, 2009b, 2009a).

Visando a predição do funcionamento natural, modelos são usados para representação do escoamento superficial. Entretanto, na elaboração desses modelos uma série de dados de entrada são requeridos para a obtenção dos resultados, como o uso e a ocupação da terra, dados climatológicos, geológicos, geomorfológicos e do tipo de solo (Woodward et al., 2002; Mello et al., 2003; USDA-NRCS, 2004a; Hawkins et al., 2009).

Dados hidrológicos e principalmente dados detalhados de escoamento superficial em bacias hidrográficas do Cerrado são escassos. Sendo assim, métodos de conhecimento do escoamento superficial desenvolvidos em outras condições climáticas são aplicados para a determinação do escoamento superficial nessa área. Porém, os resultados são questionáveis, visto que esses métodos foram elaborados a partir de estudos em regiões de clima temperado, como o Método SCS-CN (USDANRCS, 2002, 2004a, 2004b; Woodward et al., 2002). Neste sentido, justifica-se a criação de modelos representativos do processo de escoamento superficial e da infiltração de água em vertentes de bacias hidrográficas para as condições climáticas do território brasileiro, o que auxiliaria na elaboração de estratégias e na execução de propostas de gestão do meio ambiente.

O Método SCS-CN, desenvolvido pelo SCS (EUA), atualmente denominado Natural Resources Conservation Service (NRCS), tem como objetivo determinar o volume de escoamento superficial e a capacidade de armazenamento de água do solo em pequenas bacias hidrográficas. Contudo, esse modelo foi desenvolvido com dados adquiridos sob condições edafoclimáticas do território dos Estados Unidos (como índices de abstração inicial e armazenamento de água no solo), onde os parâmetros utilizados pela metodologia não apresentam dados com percentual de erro mínimo, convertendo-se em valores muito diferentes se comparados às condições físicas e climáticas de regiões tropicais, incluindo grande parte do território do Brasil.

A abstração inicial (la) define-se como a água evaporada diretamente para a atmosfera durante e após os eventos pluviométricos, a água interceptada pela vegetação, o armazenamento superficial e a infiltração inicial, instantes antes ao início do processo de escoamento superficial (runoff) (Woodward et al., 2002; USDA-NRCS, 2004a; Hawkins et al., 2009).

Correlacionado o volume de la com a capacidade de armazenamento de água do solo (S) tem-se os índices de abstração inicial (relação la/S ou $\lambda$ ). Alterações nos índices 
de abstração inicial e na capacidade de armazenamento de água do solo levam, consequentemente, a mudanças nos próprios valores $\mathrm{CN}$, pois os valores $\mathrm{CN}$ das tabelas do NRCS consideram a abstração como $20 \%$ da capacidade de armazenamento de água do solo, ou seja, la=0,2.S. Portanto, se novos índices de abstração inicial são obtidos, geram-se mudanças na própria capacidade de armazenamento de água do solo e nos valores CN. Deste modo, índices de abstração inicial e valores CN para cada região devem ser obtidos de forma a gerar melhor estimativa do escoamento superficial e da capacidade de armazenamento de água do solo de cada localidade.

Pesquisas que objetivem determinar os índices de abstração inicial e os valores CN podem fornecer alternativas aos valores dos parâmetros e dos índices originalmente adotados pelo Método SCS-CN. Inúmeras pesquisas são realizadas com a finalidade de obtenção de dados de la e do valor $\mathrm{CN}$, o que pode levar a uma melhora na estimativa do escoamento superficial e da capacidade de armazenamento de água do solo, contribuindo para uma melhor gestão das bacias hidrográficas e do meio ambiente (Jiang, 2001; Mello et al., 2003; Baltas et al., 2007; Elhakeem; Papanicolaou, 2009; D’Asaro; Grillone, 2012, 2015, 2010).

Portanto, recomenda-se quando os dados de precipitação e de escoamento superficial estiverem disponíveis - a calibração dos índices de abstração inicial e dos valores CN para, posteriormente, empregar-se o Método SCS-CN, objetivando a estimativa do escoamento superficial da bacia hidrográfica em questão. Isso se dá em virtude de os índices de abstração inicial e consequentemente os valores CN serem considerados parâmetros regionais e climáticos.

Para reduzir o risco de erros na seleção dos valores $\mathrm{CN}$ em tabelas do National Engineering Handbook-4 (NEH-4), recomenda-se a criação de referências a partir da determinação de valores $\mathrm{CN}$ com base em dados de precipitação e de escoamento superficial de bacias hidrográficas locais, a fim de confirmar a escolha dos valores $\mathrm{CN}$ das tabelas do NEH-4 com maior confiabilidade. Modelos globais, como o Método SCS-CN, precisam ser aperfeiçoados a partir de dados obtidos localmente e regionalmente, pois a escala de abrangência desses métodos ultrapassa a escala em que os dados utilizados para o seu estabelecimento foram obtidos.

Assim, a alimentação com dados locais na metodologia pode auxiliar na melhor gestão das bacias hidrográficas do território brasileiro, proporcionando melhor estimativa do escoamento superficial e da capacidade de armazenamento de água do solo. Os diversos usos da terra em bacias hidrográficas do Bioma Cerrado brasileiro precisam ter os valores da la determinados para que o processo de escoamento superficial e suas consequências para o solo possam ser mais bem conhecidos, além de estimar a recarga d'água subterrânea, pois quanto maiores os índices da abstração inicial, menores serão o volume de escoamento superficial e vice-versa. Valores CN e índices de abstração inicial obtidos a partir de simuladores de chuva podem fornecer dados para uma melhor aplicação do Método SCS-CN e, com isso, fornecer uma melhor estimativa do escoamento superficial e da capacidade de armazenamento de água do 
solo. Estudos das condições das bacias hidrográficas podem ser realizados de maneira rápida e eficaz com a utilização de simuladores de chuva, e pesquisas em série podem fornecer dados que comparados a dados de outros estudos podem melhor definir os parâmetros do Método SCS-CN.

O objetivo deste artigo consiste em apresentar uma metodologia para a determinação dos parâmetros do Método SCS-CN, a abstração inicial, o escoamento superficial e os valores CN para a cultura de café Arábica inserida em ambiente de cerrado, por meio do uso de um simulador de chuvas para aquisição de dados de forma mais controlada, possibilitando testar sua utilização para a calibração do modelo.

\section{Procedimentos Metodológicos}

Na Figura 1, observa-se a localização da bacia hidrográfica do córrego do Glória (Uberlândia - MG) onde foram realizadas as simulações de chuva no uso e ocupação da terra Cafezal. O solo predominante da área é o Latossolo Vermelho Distrófico com textura argilosa predominante, a topografia do relevo é levemente ondulada (Bastos, Melo, 2008; da Silva et al., 2008), apresentando declividade de 14\% na área onde foram instaladas as parcelas.

Mapa de Uso e Ocupação da Bacia do Córrego do Glória - Uberlândia, MG

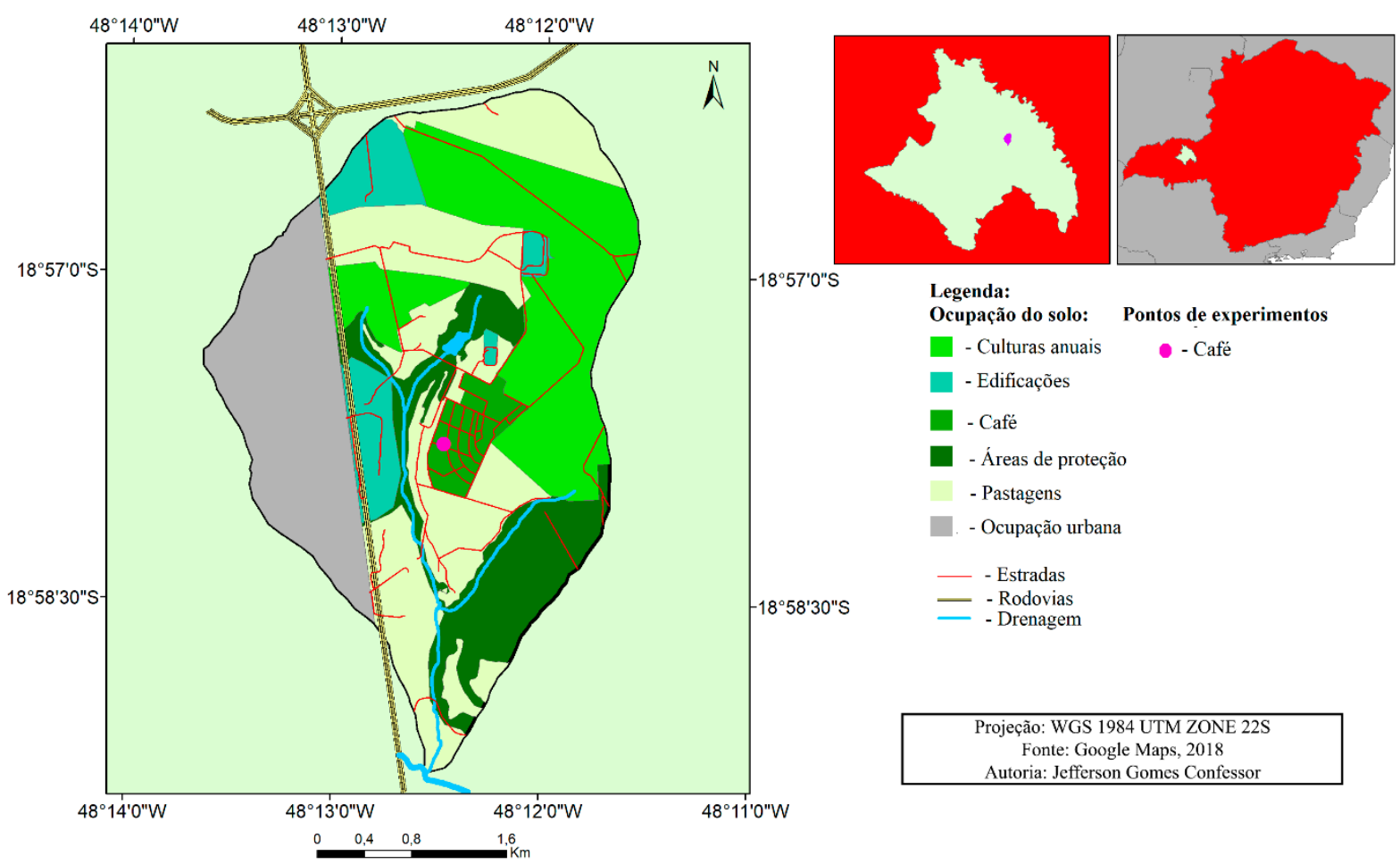

Figura 1 - Localização e usos e ocupações da área de estudo.

Org.: Confessor (2018).

Os dados do volume de abstração inicial, os índices de abstração inicial e o valor CN no cafezal (café arábica) foram obtidos em parcelas experimentais instaladas previamente no cultivar. $\mathrm{O}$ experimento foi realizado no Setor de Cafeicultura da 
Fazenda Experimental do Campus Glória (Universidade Federal de Uberlândia UFU). As plantas de café da área apresentaram altura média de 2,4 metros, com espaçamento entre linhas de $3 \mathrm{~m}$ e distância entre as plantas de $0,70 \mathrm{~m}$.

A área do cafezal, onde foi realizado o experimento, caracteriza-se por cultivos em curvas de nível. As simulações no cafezal ocorreram em dois períodos analisados, com duas simulações em cada um dos períodos, a saber: outono-inverno (seco) e primavera-verão (úmido). As simulações no período do outono-inverno foram de 30 minutos e no período da primavera-verão foram de 60 minutos cada.

As simulações ocorreram com um intervalo de 15 minutos entre as mesmas, sendo este tempo necessário para cessar o escoamento superficial. Com duas simulações no mesmo dia, pode-se evidenciar a influência da precipitação antecedente nos valores $\mathrm{CN}$ e, por sua vez, na produção de fluxos superficiais.

1.1 Volume de abstração inicial, volume de escoamento superficial, capacidade de armazenamento de água do solo, valor $\mathrm{CN}$ e índice de abstração inicial

Utilizou-se de um simulador de chuva previamente calibrado (Confessor, 2019) para a coleta dos dados de escoamento superficial, o tempo e o volume de abstração inicial. Posteriormente, foram obtidos os dados da capacidade de armazenamento de água do solo (S), os índices de abstração inicial (relação la/S ou $\lambda$ ) e os valores $C N$.

A capacidade de armazenamento de água do solo foi determinada a partir da utilização dos dados de precipitação, escoamento superficial e a partir de índices de abstração inicial. Neste sentido, foram utilizados três procedimentos para a obtenção de S.

Os volumes de la expostos na pesquisa para cada evento analisado foram correlacionados com as capacidades de armazenamento de água, visando a obtenção dos índices de abstração inicial, ou seja, os índices foram gerados a partir da correlação entre a capacidade de armazenamento determinada por meio do uso do simulador de chuvas e fórmulas existentes, que consideraram diferentes índices de abstração inicial.

Vale ressaltar que, em algumas simulações, o volume de la utilizado para correlacionar com as capacidades de armazenamento de água do solo e, posteriormente, produzir os índices de abstração inicial foi o mesmo em todas as operações, ou seja, aquele único volume captado em cada teste realizado nos usos e a ocupação da terra experimentados, e que foi correlacionado às diferentes capacidades de armazenamento de água do solo para produzir os índices de abstração inicial.

Como mencionado anteriormente, 0 volume de escoamento superficial foi determinado pelo tempo, ou seja, desde o início da simulação de chuva até o instante em que se iniciou o escoamento superficial. Conhecendo-se o volume de precipitação em uma hora, determinou-se o volume com base no tempo. As capacidades de armazenamento de água do solo utilizadas para produzir os índices de abstração inicial foram determinadas de acordo com os seguintes procedimentos: 
$1^{\circ}$ A diferença entre o volume precipitado e o volume escoado pela calha determinou a capacidade de armazenamento de água do solo com o método nomeado aqui como "simulador de chuva (Ssi)" (Eq. 1).

$$
S s i=P-Q
$$

Eq. 1

Onde:

Ssi = capacidade de armazenamento de água do solo do simulador de chuva;

$\mathrm{P}=$ Precipitação; $\mathrm{e}$

$Q=$ Escoamento superficial.

Relacionando-se o dado da abstração inicial (volume de la) com o dado de Ssi, fixouse o índice de abstração inicial com o simulador de chuva ( $\lambda$ si) para cada evento pluviométrico analisado e/ou para cada calha.

$2^{\circ} \mathrm{A}$ partir do $\lambda \mathrm{si}$, determinou-se uma nova capacidade de armazenamento de água do solo, mas com os índices de abstração inicial obtidos com o simulador de chuva, mediante a seguinte equação:

$$
S \lambda=\frac{\left[2 \lambda P+Q(1-\lambda)-\sqrt{\left\{[Q(1-\lambda)]^{2}+4 \lambda Q P\right\}}\right]}{\left(2 \lambda^{2}\right)}
$$

Onde:

$\mathrm{S}$ = capacidade de armazenamento de água do solo $(\mathrm{mm})$;

$\mathrm{P}=$ precipitação $(\mathrm{mm})$;

$\lambda=$ relação la/S;

$\mathrm{Q}=$ escoamento superficial $(\mathrm{mm})$;

Fonte: Hawkins, Ward, Woodward e Van Mullem (2009, p. 74).

Com a Equação 2 foi possível determinar $S$ com o índice de abstração inicial obtido com o simulador de chuva ( $\lambda$ si). Essa nova capacidade de armazenamento, alcançada com o índice de abstração inicial do simulador de chuva e com dados de precipitação e de escoamento superficial obtidos na pesquisa, foi obtida com a finalidade de comparação com as outras capacidades de armazenamento de água do solo.

Utilizando-se a Equação 2, determinou-se uma nova capacidade de armazenamento de água do solo com a abstração inicial a $20 \%$ de $S(l a=0,2 \cdot S)$ para a avaliação dos efeitos da alteração do índice de abstração inicial na determinação do armazenamento da água e, consequentemente, nos valores CN. Esse armazenamento de água do solo com la $=0,2 \cdot S$, aqui denominado 'Sp-q', produziu um novo índice de abstração inicial denominado ' $\lambda p-q$ ', obtido a partir da correlação entre o volume de la definido para as simulações e o armazenamento de água do solo denominado de 'Sp-q'. 
Com a obtenção das três diferentes capacidades de armazenamento de água do solo, nas simulações realizadas na cultura de café, foram determinados os respectivos valores CN por meio da Equação 3.

$$
C N=\frac{1000}{10+\frac{S}{25,4}}
$$

Onde:

$\mathrm{CN}=$ valor $\mathrm{CN} ; \mathrm{e}$

$\mathrm{S}=$ capacidade de armazenamento de água do solo $(\mathrm{mm})$.

Fonte: USDA-NRCS (2004a, p. 4)

Portanto, cada capacidade de armazenamento dessa água alcançada no uso e ocupação da terra selecionado para cada evento pluviométrico e em cada parcela produziu, respectivamente, um valor $\mathrm{CN}$ que foi utilizado para comparação com os valores $\mathrm{CN}$ encontrados no NRCS.

Os valores $\mathrm{CN}$ disponibilizados em tabelas e em gráficos pelo NRCS foram denominados como valores CNtb e utilizados para comparação dos valores CNs obtidos na presente pesquisa, ou seja, o valor CNtb determinado para o uso e ocupação da terra Cafezal será comparado aos valores $\mathrm{CN}$ coletados com os dados de precipitação, escoamento superficial e a abstração inicial alcançados com o uso do simulador de chuva. Foram realizadas analogias entre as diversas capacidades de armazenamento de água do solo, os seus respectivos valores $\mathrm{CN}$ para as parcelas experimentais.

A condição antecedente de umidade (AMC) foi definida com base no volume de precipitação pluviométrica acumulada nos cinco dias anteriores à realização dos testes e, portanto, sendo possível selecionar os valores $\mathrm{CNtb}$ contidos nas tabelas do NRCS nas três condições antecedentes de umidade, ou seja, AMC I, AMC II e AMC III. Também foram comparados os índices de abstração inicial coletados no Cafezal com aqueles adotados originalmente pela metodologia SCS-CN e também obtidos em outras pesquisas.

\subsection{Definição do grupo hidrológico do solo e da condição hidrológica}

Foram definidos os grupos hidrológicos do solo de acordo com a classificação textural das amostras coletadas no cafezal nas profundidades de $0-15 \mathrm{~cm}$ e $15-30 \mathrm{~cm}$ com auxílio de um trado. As análises foram realizadas no LAGES (Laboratório de Geomorfologia e Erosão dos Solos - Universidade Federal de Uberlândia) a partir da metodologia disponibilizada pela EMBRAPA (1997).

Os grupos hidrológicos dos solos foram determinados conforme a classificação da textura proposta pelo USDA-NRCS (1986) e USDA-NRCS (2009). Para a definição do valor CN nas tabelas do NRCS necessita-se da definição do grupo hidrológico do solo, pois este representa uma das variáveis para a definição dos valores $\mathrm{CN}$ com base nas 
tabelas do (USDA-NRCS, 2004b). A partir da definição do grupo hidrológico do solo dos usos e ocupação da terra foram obtidos os valores $\mathrm{CNtb}$ mediante as tabelas do (USDA-NRCS, 2004b).

A área do cafezal foi classificada como pertencente ao grupo hidrológico do solo "C". Concomitante à determinação do grupo hidrológico do solo foi quantificada a precipitação antecedente aos cinco dias anteriores à simulação por meio de uma estação pluviométrica instalada no cafezal, visando definir a condição antecedente de umidade, conforme orientações do SCS. O período do outono-inverno foi caracterizado como de repouso vegetativo e a condição antecedente de umidade I (AMC I) foi determinada quando da ocorrência de menos de $13 \mathrm{~mm}$ de chuva nos cinco dias anteriores. A AMC II foi determinada como a precipitação acumulada nos cinco dias anteriores entre 13 e $28 \mathrm{~mm}$ de chuva e a AMC III quando do acúmulo de precipitação maior do que $28 \mathrm{~mm}$ nos cinco dias anteriores.

Para o período da primavera-verão (período vegetativo), a AMC I (seco) foi definida com volume de chuva menor do que $36 \mathrm{~mm}$ acumulado nos cinco dias anteriores, 0 AMC II (condições médias de umidade) com o acúmulo de chuva entre 36 e $54 \mathrm{~mm}$ nos cinco dias anteriores à simulação. O AMC III (condição de umidade elevada) foi definido quando o volume precipitado nos cinco dias foi maior do que $54 \mathrm{~mm}$. Assim, conforme orientação do SCS, foram definidas as condições antecedentes de umidade estimando o valor $\mathrm{CN}$ tb comparado aos valores $\mathrm{CN}$ derivados da pesquisa.

Nos Capítulos 8 e 9 do USDA-NRCS (2002, 2004b), é apresentada a definição da condição hidrológica do solo, pois sua condição define os valores $\mathrm{CN}$ nas tabelas do NRCS (CNtb), permitindo a classificação do uso da terra analisado. O cafezal foi classificado como pertencente ao grupo hidrológico do solo (HSG) "C", com um percentual de $20 \%$ a $40 \%$ de argila e $50 \%$ a $90 \%$ de areia. Nas tabelas do NRCS, o cafezal foi classificado como Woods-grass combination (orchard or tree farm), com $50 \%$ da área com madeira e outros $50 \%$ com pastagem, podendo ser classificadas como boa, regular e pobre. As áreas pobres são pastoreio intensivo e regularmente queimada com pequenas árvores e os arbustos são retirados. As áreas regulares sofrem pastoreio, mas não sofrem queimadas, e as áreas boas não sofrem pastoreio e possuem superfície recoberta por arbusto e serapilheira; a condição hidrológica good; considerando esses aspectos do uso da terra café o valor CNtb na condição antecedente de umidade II foi 72.

Como mencionado anteriormente, a condição hidrológica define-se pela combinação de fatores que determinam o escoamento superficial e o processo de infiltração, como cobertura vegetal e dossel, quantidade de cobertura durante 0 ano e palhada. A categoria 'ruim' seria caracterizada por fatores que impedem ou limitam a infiltração e favorecem o escoamento superficial, e a categoria 'bom' seria relacionada a fatores que induzem a infiltração e, consequentemente, limitam a formação do escoamento superficial (USDA-NRCS, 2004b). 


\subsection{Simulador de chuva, equipamentos e materiais utilizados nos testes de} simulação de chuva

O simulador de chuva utilizado neste artigo expõe uma variação do modelo apresentado por Luk, Abrahams e Parsons (1986), o qual foi calibrado conforme visto em Confessor e Rodrigues (2018) e Confessor (2019). O simulador constitui-se por uma tubulação de aço galvanizado de $19 \mathrm{~mm}$ de diâmetro com 4,6 $\mathrm{m}$ de altura e um prolongamento da tubulação aos bicos aspersores com $5 \mathrm{~m}$ de comprimento (Figura $2-\mathrm{B}$ ), que se divide em partes iguais para acoplagem de dois bicos aspersores (Figura 2 - C) de marca FullJet $1 / 2 \mathrm{HH}-30$ WSQ. A sustentação da tubulação d'água foi realizada por duas hastes laterais com a finalidade de dar suporte à tubulação que conduz a água aos bicos aspersores (Figura $2-A$ ), sustentando a tubulação para 0 posicionamento vertical dos bicos aspersores em relação ao nível do solo.

O posicionamento dos bicos a uma altura de 4,6 $\mathrm{m}$ em relação à superfície do terreno aliado à pressão constante de serviço necessária para acionamento do equipamento garantiram à chuva simulada assemelhar-se a uma precipitação natural. A distância entre um suporte lateral ao outro é de $5 \mathrm{~m}$, segmentando em partes para facilitar o transporte e a instalação, podendo ser observados outros detalhes na Figura 2.
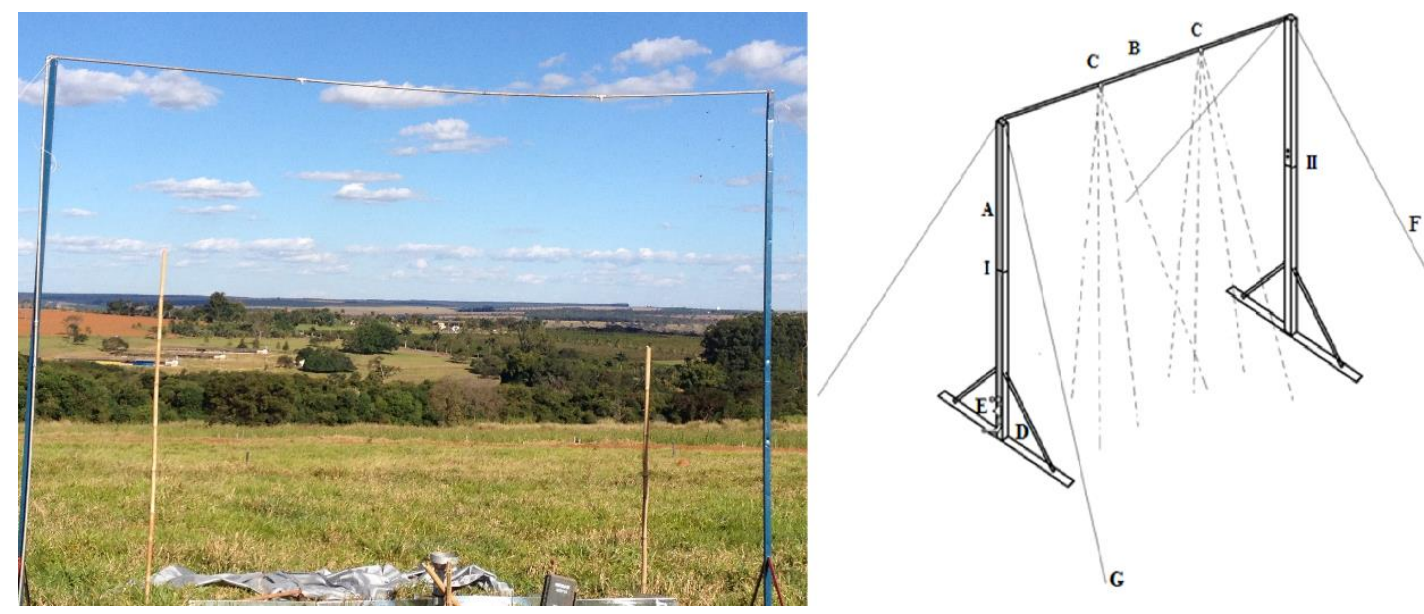

Figura 2 - Direita - Croqui do simulador de chuvas utilizado e os seus componentes; Esquerda Fotografia do simulador de chuvas em campo; A - Haste principal; B - Haste conectora aos bicos aspersores; C - Bico aspersor; D - Registro d'água; E - Manômetro; F - Cabo de sustentação; G Gancho fixo ao chão; I e II - conexões da base de sustentação do simulador;

Org.: Confessor (2019).

O simulador de chuva confeccionado constitui-se de hastes localizadas em ambos os lados, possuindo em suas bases suportes para manter o simulador fixo ao chão. $\mathrm{Na}$ base do cano condutor de água, há um registro d'água e um manômetro para o controle da pressão. Para uma melhor sustentação e segurança na operação do simulador de chuva são utilizados cabos de poliéster presos à superfície por meio de ganchos de ferro.

A água é conduzida a partir de um reservatório em direção aos bicos aspersores por uma motobomba movida a gasolina de 4,5 HP de potência. A distância entre os dois 
bicos aspersores é de $2 \mathrm{~m}$ e o diâmetro médio das gotas (D50) é de $2 \mathrm{~mm}$. Para o armazenamento da água foram utilizadas 3 caixas d'água de polietileno com capacidade de $500 \mathrm{~L}$ cada. A motobomba conduzia a água das caixas d'água por meio de mangueiras que se conectavam ao simulador de chuva, com pressão no manômetro de 12 psi, capaz de produzir uma precipitação média de $66,5 \mathrm{~mm} / \mathrm{h}$. Deste modo, a constância na pressão de serviço gera uma intensidade homogênea nas simulações. Na Figura 3, observa-se o simulador de chuva e as calhas instaladas no Cafezal.

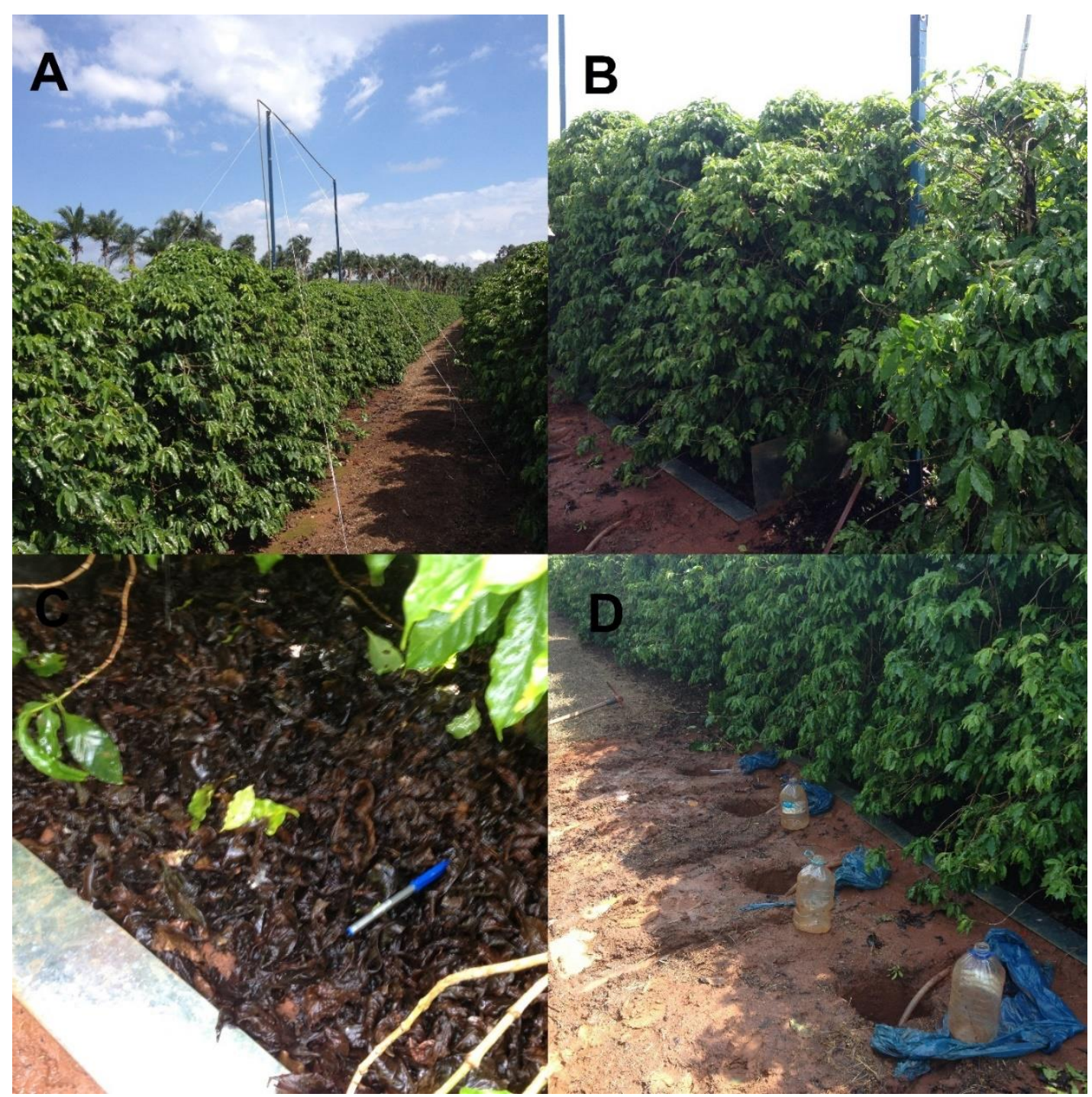

Figura 3 - Simulador de chuva instalado no Cafezal; A - Simulador de chuva instalado no Cafezal; B - Aspectos das calhas coletoras e do simulador no Cafezal; C - Serrapilheira e calha coletora instalada no Cafezal; D - Recipientes de armazenagem do escoamento superficial.

Org.: Carvalho (2018).

O simulador foi posicionado seguindo as linhas de plantio, inserindo as parcelas de captação dos fluxos abaixo das plantas de café, num total de quatro, dispostas lado a lado (Figura 4). O escoamento foi captado por meio de calhas coletoras e direcionado a recipientes de armazenamento para leitura. No período do outono-inverno, foi 
considerado apenas um volume de la (primeiro fluxo escoado entre as quatro parcelas); e no período da primavera-verão, foram avaliados volumes de la para cada parcela Carvalho (2018).
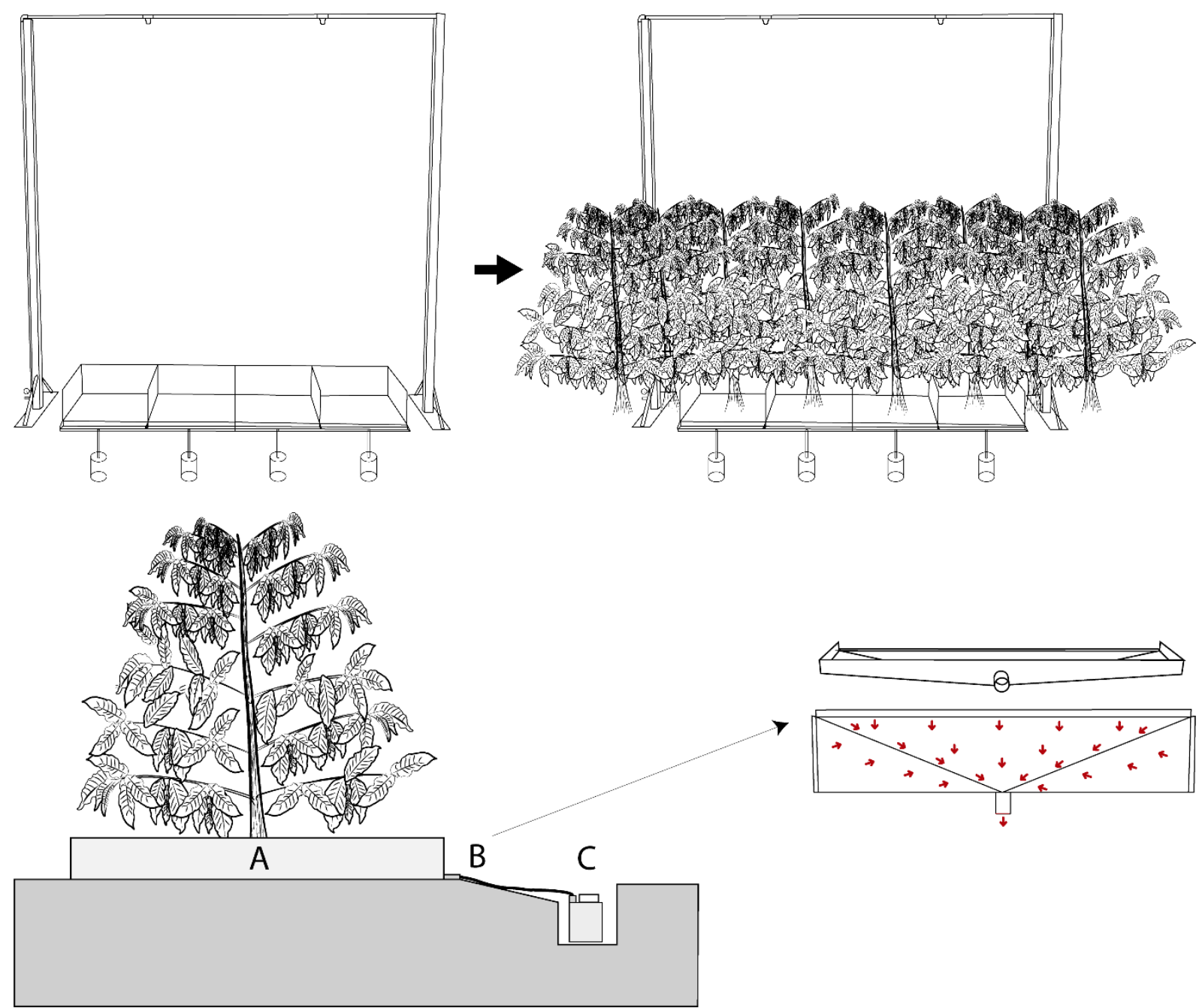

Figura 4: Simulador de chuvas e parcelas de erosão posicionadas na linha de plantio de café.

Parcela de erosão (A); Calha coletora de fluxos superficiais (B); Galão de coleta de fluxos superficiais (C).

Org.: Autores.

Os simuladores de chuva possibilitam a reprodução de chuvas naturais, pois é possível regular a intensidade da chuva, o tamanho da gota, a homogeneidade na área aplicada, a velocidade de queda e sua reprodução por inúmeras vezes (Elhakeem, Papanicolaou, 2012).

\section{Resultados e Discussão}

\subsection{Primeira simulação - outono-inverno}

A simulação com intensidade de $66,5 \mathrm{~mm} / \mathrm{h}$ foi replicada por 30 minutos, proporcionando uma precipitação efetiva de $33,25 \mathrm{~mm}$ sobre a área. A Tabela 1 contém os dados do volume de escoamento superficial, o volume da abstração inicial, 
do valor $\mathrm{CN}$ e os índices de abstração inicial para o uso da terra café - período outonoinverno.

Tabela 1: Índice de la, S e CN para o uso café - outono-inverno

\begin{tabular}{|c|c|c|c|c|c|c|c|c|c|}
\hline CALHAS & $\mathrm{Q}(\mathrm{mm})$ & $\mathrm{la}(\mathrm{mm})$ & $\mathrm{Ssi}(\mathrm{mm})$ & $\mathrm{CNsi}$ & $\lambda \mathrm{si}$ & $\mathrm{Sp-q}(\mathrm{mm})$ & $\lambda \mathrm{p}-\mathrm{q}$ & $\mathrm{CNp}-\mathrm{q}$ & $\mathrm{S} \lambda(\mathrm{mm})$ \\
\hline 1A & 1,58 & 4,43 & 31,68 & 89 & 0,14 & 99,60 & 0,04 & 72 & 129,71 \\
\hline 1B & 0,18 & 4,43 & 33,08 & 88 & 0,13 & 141,01 & 0,03 & 64 & 202,99 \\
\hline 1C & 1,46 & 4,43 & 31,79 & 89 & 0,14 & 101,55 & 0,04 & 71 & 133,01 \\
\hline 1D & 0,63 & 4,43 & 32,63 & 89 & 0,14 & 121,09 & 0,04 & 68 & 167,01 \\
\hline MÉDIA & 0,96 & 4,43 & 32,30 & 89 & 0,14 & 115,81 & 0,04 & 69 & 158,18 \\
\hline
\end{tabular}

Q - escoamento superficial; la - abstração inicial; Ssi - capacidade de armazenamento de água do solo; $\lambda$ si - índice de la/Ssi; CNsi - valor CN; Sp-q - capacidade de armazenamento de água do solo com la $=0,2 ; \lambda p-q$ - índice de la/Sp-q; $C N p-q$ - valor $C N ; S \lambda$ - capacidade de armazenamento de água do solo com relação ao $\lambda$ si.

A primeira simulação de chuva no cafezal apresentou baixo volume de escoamento superficial com $0,18 \mathrm{~mm}$ na calha $1 \mathrm{~B}$ e maior volume de escoamento superficial de $1,58 \mathrm{~mm}$. Os baixos volumes escoados são reflexos da densa cobertura vegetal produzida pelas plantas de café, e a amplitude dos dados coletados se relaciona pelo arranjo estrutural vegetativo produzido pelos hábitos de crescimento das plantas e a forma de plantio, onde o escoamento pelos galhos das plantas redireciona o fluxo da d'água de forma a se concentrar ou não em determinadas áreas, o que explica a variação do escoamento superficial entre as calhas.

O volume de abstração inicial foi $4,43 \mathrm{~mm}$ e a capacidade de armazenamento de água do solo do simulador de chuva (Ssi) apresentou pequena variação de 31,68 mm a 33,08 mm em consonância com o escoamento superficial. $O$ índice de abstração inicial do simulador de chuva $(\lambda s i)$ apresentou pequena variação, de 0,13 a 0,14 , com média de 0,14 , próximo aos 0,2 , mas inferior a $\lambda=0,2$ adotado pela metodologia SCSCN.

O valor CNsi demonstrado para todas as calhas foi de 89,17 pontos a mais do que 0 valor $\mathrm{CNtb}-\mathrm{AMC} \|(\mathrm{CNtb}=72)$. Entretanto, considerando-se que a simulação se enquadra na condição antecedente de umidade III (devido ao pré molhamento realizado 24 horas antes), o valor CNtb eleva-se de 72 para 86, distando apenas 3 pontos da média do valor CNsi dessa simulação. O armazenamento de água do solo com $\lambda=0,2(\mathrm{Sp}-\mathrm{q})$ variou de $99,60 \mathrm{~mm}$ a $141,01 \mathrm{~mm}$, com média de 115,81 mm; os valores CNp-q variaram de 64 a 72 com média de 69, inferior ao valor CNtb - AMC II.

Neste sentido, os valores CNsi foram próximos aos do CNtb na condição antecedente de umidade III e os do CNp-q foram próximos àqueles do CNtb na condição antecedente de umidade II. Como nas outras simulações realizadas na pesquisa, a nova capacidade de armazenamento de água do solo com o índice de abstração inicial do simulador de chuva foi maior do que Ssi e Sp-q, oscilando para essa simulação de $129,71 \mathrm{~mm}$ a 202,99 mm, o que, consequentemente, reduz os valores CN. O índice de abstração inicial com Sp-q apresentou média de 0,04, mais de três vezes inferior ao $\lambda$ si devido ao maior armazenamento de água de Sp-q. Verifica-se que $\lambda$ si foi mais 
próximo a $\lambda=0,2$. Entretanto, $\lambda p-q$ foi inferior ao índice oficial da abstração inicial como $20 \%$ da capacidade de armazenamento.

Diante das constatações, observa-se a interferência da condição antecedente de umidade nos valores $\mathrm{CN}$ e, consequentemente, interferência da la na capacidade de armazenamento de água do solo e nos valores CN. A abstração inicial desta simulação correspondeu a $13,7 \%$ da capacidade de armazenamento do simulador de chuva (Ssi). Já para a capacidade de armazenamento Sp-q, o volume abstraído corresponde, aproximadamente, a apenas 4\% de Sp-q, inferior aos 20\% recomendados, indicando a elevada capacidade destes usos em reter as águas pluviais. Neste sentido, podemos observar a interferência da la nas capacidades de armazenamento de água do solo e nos valores CNs derivados.

\subsection{Segunda simulação - outono-inverno}

A segunda simulação da cultura do café foi realizada 30 minutos após o término da primeira. Na Tabela 2, são apresentados os dados do volume de escoamento superficial, o volume de abstração inicial, o volume de armazenamento de água pelo solo e os respectivos valores $\mathrm{CN}$. Também podem ser verificados os índices de abstração inicial obtidos a partir do volume de abstração inicial correlacionados às capacidades de armazenamento de água pelo solo.

Tabela 2: Volume de escoamento superficial, de abstração inicial e capacidade de armazenamento de água, valores $\mathrm{CN}$ e índices de abstração inicial do café - período do outono-inverno

\begin{tabular}{|c|c|c|c|c|c|c|c|c|c|}
\hline CALHAS & $\mathrm{Q}(\mathrm{mm})$ & la $(\mathrm{mm})$ & Ssi $(\mathrm{mm})$ & CNsi & $\lambda$ si & Sp-q $(\mathrm{mm})$ & $\lambda p-q$ & CNp-q & $S \lambda(\mathrm{mm})$ \\
\hline 2A & 2,45 & 4,25 & 30,81 & 89 & 0,14 & 86,96 & 0,05 & 74 & 111,91 \\
\hline 2B & 1,33 & 4,25 & 31,93 & 89 & 0,13 & 104,03 & 0,04 & 71 & 141,60 \\
\hline 2C & 0,94 & 4,25 & 32,32 & 89 & 0,13 & 112,47 & 0,04 & 69 & 156,91 \\
\hline 2D & 0,75 & 4,25 & 32,50 & 89 & 0,13 & 117,36 & 0,04 & 68 & 165,95 \\
\hline MÉDIA & 1,37 & 4,25 & 31,89 & 89 & 0,13 & 105,20 & 0,04 & 71 & 144,09 \\
\hline
\end{tabular}

Q - escoamento superficial; la - abstração inicial; Ssi - capacidade de armazenamento de água do solo; $\lambda$ si - índice de la/Ssi; CNsi - valor CN; Sp-q - capacidade de armazenamento de água do solo com la=0,2; $\lambda p-q$ - índice de la/Sp-q; CNp-q - valor CN; S $\lambda$ - capacidade de armazenamento de água do solo com relação ao $\lambda$ si.

Observa-se que mesmo depois de ocorrer uma precipitação de 33,25 mm 30 minutos antes, o volume de abstração inicial continua praticamente igual, com média de $13 \%$ de abstração inicial com a capacidade de armazenamento Ssi e 4\% para a capacidade de armazenamento Sp-q. Esses resultados indicam a elevada capacidade de absorção/retenção de água do café com essas características, reduzindo consideravelmente o escoamento superficial e suas consequências em uma bacia hidrográfica. Outros usos da terra que levam à compactação do solo, como uso urbano aliado a outros fatores, elevam o escoamento superficial.

De modo semelhante à primeira simulação realizada na cultura do café, a segunda simulação apresentou consideráveis diferenças do escoamento superficial entre as calhas, variando de $0,75 \mathrm{~mm}$ a $2,45 \mathrm{~mm}$, podendo ser justificado pelo escoamento da água pelas galhas das plantas que, pelo seu porte, direciona o fluxo de água orientado 
de uma calha para outras, de forma análoga ao que ocorre em uma floresta, e a média do volume de escoamento superficial foi de $1,37 \mathrm{~mm}$.

Observa-se um maior escoamento superficial se comparado com a primeira simulação, provavelmente devido ao início da saturação do solo. Devido ao fato de essa simulação ser realizada em 30 minutos, verificou-se menor capacidade de armazenamento de água do solo e, consequentemente, maior valor CNsi. Na primeira simulação, do período do outono-inverno, verificou-se na calha 1B o valor CNsi 88 . Na segunda simulação outono-inverno no café, todas as calhas foram CNsi 89.

O volume de abstração inicial foi pouco menor do que o registrado para a primeira simulação na cultura do café, com $4,25 \mathrm{~mm}$, e o armazenamento de água pelo solo oscilou de $30,81 \mathrm{~mm}$ a $32,50 \mathrm{~mm}$, com média de 31,89 , sendo o armazenamento de água do solo pouco inferior ao volume registrado na primeira simulação realizada. Assim, os índices de abstração inicial obtidos com a capacidade de armazenamento de água do simulador foram praticamente os mesmos apresentados na primeira simulação, com diferença de $1 \%$ na média, com $\lambda=0,13$. A média do índice de abstração da segunda simulação no uso da terra café foi próximo à primeira e pouco inferior ao adotado originalmente pelo SCS-CN.

Os valores $\mathrm{CNsi}=89$ foram os mesmos apresentados na primeira simulação, com três pontos superiores ao valor CNtb - AMC III definidos para a cultura perene do café $(\mathrm{CNtb}=86)$. O armazenamento de água do solo com a la=0,2·S, semelhante ao da outra simulação no café, foi em média três vezes maior do que a capacidade de armazenamento definida com os dados do simulador apenas, com média de 105,20 $\mathrm{mm}$, e o seu índice de abstração inicial foi o mesmo para a primeira simulação, porém, da mesma forma inferior ao índice de abstração inicial com o armazenamento obtido com o simulador de chuva.

De acordo com Elhakeem e Papanicolaou (2009), os valores CN encontrados no verão em campos agrícolas de lowa (EUA) com a utilização de simulador de chuva foram próximos aos valores $\mathrm{CNs}$ tabelados. Contudo, no outono, essa diferença entre os valores CNs tabelados e CNs estimados apresentaram distinções significativas. Tal fato foi atribuído à palhada no campo após a colheita no outono. Salienta-se que a cobertura de resíduos e a umidade do solo são mais importantes na determinação do valor $\mathrm{CN}$ do que o manejo do solo e o tipo de cultura.

Devido à maior capacidade de armazenamento com la=0,2·S, os valores $\mathrm{CNp}-\mathrm{q}$ foram inferiores aos valores CNsi, variando de 68 a 74, com média de 71, inferiores ao valor $\mathrm{CNtb}$ na condição antecedente de umidade III $(\mathrm{CNtb}=86)$, e valores $\mathrm{CNsi}$ próximos ao $\mathrm{CNtb}$ na condição antecedente de umidade II $(\mathrm{CNtb}=72)$. A capacidade de armazenamento de água com o índice de abstração inicial do simulador de chuva foi em média mais de $35 \mathrm{~mm}$ maior do que Sp-q, variando de 111,91 a 165,95, alterando consideravelmente $54,04 \mathrm{~mm}$ entre as calhas 2A e 2D.

Segundo Elhakeem e Papanicolaou (2009), a la aumenta à medida que houver aumento da capacidade de armazenamento de água do solo (S) e redução de 
umidade. Observou-se, ainda, que quanto maiores foram os valores $\mathrm{CN}$, menor foi a condutividade hidráulica saturada e vice-versa, e a la não foi proporcional à capacidade de armazenamento de água do solo. Em alguns usos da terra, verificouse que à medida que uma redução do volume de la era observada, maiores foram as capacidades de armazenamento de água do solo.

\subsection{Primeira simulação - primavera-verão}

$\mathrm{Na}$ Tabela 3, observam-se os dados da simulação realizada no período da primaveraverão.

Tabela 3: Volume de escoamento superficial, de abstração inicial e capacidade de armazenamento de água, valores $\mathrm{CN}$ e índices de abstração inicial - período primavera-verão

\begin{tabular}{|c|c|c|c|c|c|c|c|c|c|}
\hline CALHAS & $\mathrm{Q}(\mathrm{mm})$ & $\mathrm{la}(\mathrm{mm})$ & $\mathrm{Ssi}(\mathrm{mm})$ & $\mathrm{CNsi}$ & $\lambda \mathrm{si}$ & $\mathrm{Sp}-\mathrm{q}(\mathrm{mm})$ & $\lambda \mathrm{p}-\mathrm{q}$ & $\mathrm{CNp}-\mathrm{q}$ & $\mathrm{S} \lambda(\mathrm{mm})$ \\
\hline 3A & 1,47 & 4,06 & 65,05 & 80 & 0,06 & 235,80 & 0,02 & 52 & 583,96 \\
\hline 3B & 2,48 & 4,90 & 64,04 & 80 & 0,08 & 211,71 & 0,02 & 55 & 427,72 \\
\hline 3C & 4,03 & 2,49 & 62,49 & 80 & 0,04 & 185,48 & 0,01 & 58 & 495,58 \\
\hline 3D & 3,08 & 3,60 & 63,43 & 80 & 0,06 & 200,41 & 0,02 & 56 & 472,07 \\
\hline MÉDIA & 2,76 & 3,76 & 63,75 & 80 & 0,06 & 208,35 & 0,02 & 55 & 494,83 \\
\hline
\end{tabular}

Q - escoamento superficial; la - abstração inicial; Ssi - capacidade de armazenamento de água do solo; $\lambda$ si - índice de la/Ssi; CNsi - valor CN; Sp-q - capacidade de armazenamento de água do solo com la =0,2; $\lambda p-q$ - índice de la/Sp-q; $C N p-q$ - valor $C N ; S \lambda$ - capacidade de armazenamento de água do solo com relação ao $\lambda$ si.

A primeira simulação na cultura do café, para o período primavera-verão, apresentou um escoamento superficial maior do que as simulações realizadas no período outonoinverno em virtude de essas simulações serem realizadas em um período de 60 minutos, apresentado mais do que o dobro da primeira simulação realizada no período outono-inverno. A primeira simulação outono-inverno apresentou média de 0,96 mm e a primeira simulação do período primavera-verão teve média de 2,76 mm.

O escoamento superficial variou de $1,47 \mathrm{~mm}$ a 4,03 $\mathrm{mm}$, com diferença de 2,56 $\mathrm{mm}$ entre uma calha e outra, o que corrobora a ideia de que em áreas de vegetação arbustivo-herbáceo é difícil definir índices de abstração inicial, pois eles são uma correlação com a capacidade de armazenamento de água do solo. O armazenamento de água do solo, neste caso, se dá em função do escoamento superficial.

Do mesmo modo que o escoamento superficial, o volume de abstração inicial também apresentou considerável variação, de $2,49 \mathrm{~mm}$ a $4,90 \mathrm{~mm}$, revelando uma diferença de $2,41 \mathrm{~mm}$ entre uma calha e outra, com uma média de $3,76 \mathrm{~mm}$. Devido a essa simulação ter sido realizada em um período de uma hora, a capacidade de armazenamento de água do simulador de chuva foi em média quase o dobro do registrado na primeira simulação, do período outono-inverno, o que implicará em valores $\mathrm{CN}$ distintos para cada período. $\mathrm{O}$ armazenamento de água do simulador de chuva variou de $62,49 \mathrm{~mm}$ a 65,05, diferença insuficiente para alterar os valores CNsi, que foram em todas as calhas igual a 80 , nove pontos inferiores ao valor CNsi média de ambas as simulações no período outono-inverno. 
Esses dados indicam a interferência do volume de precipitação e, consequentemente, do volume de escoamento superficial na determinação do valor $\mathrm{CN}$, devido a ele ser uma derivação do armazenamento de água pelo solo. O valor CNsi da primeira simulação ficou entre o valor CNtb na condição antecedente de umidade II e III para a cultura do café, o que pode indicar eficácia na definição de valores CN para bacias hidrográficas a partir de dados de precipitação e de escoamento superficial, e que a escolha de valores $\mathrm{CN}$ deve considerar definitivamente o volume de precipitação.

Neste sentido, o volume de precipitação pode interferir nos índices de abstração inicial, pois os índices somados à capacidade de armazenamento de água do simulador de chuva foram inferiores aos mesmos índices obtidos na cultura do café no período outono-inverno, os quais, na simulação do período primavera-verão, variaram de 0,04 a 0,08 , com média de 0,06 , sendo inferiores aos definidos pelo NRCS. O armazenamento de água do solo, que considera a la $=0,2 \cdot \mathrm{S}$, variou de $185,48 \mathrm{~mm}$ a $235,80 \mathrm{~mm}$, com média de $208,35 \mathrm{~mm}$, revelando um armazenamento de água do solo superior aos volumes registrados nas simulações do período outonoinverno.

Consequentemente, obteve-se um menor valor $\mathrm{CN}$ se comparado ao valor $\mathrm{CN}$ alcançado com o armazenamento do simulador de chuva e um menor índice de abstração inicial com média de 0,02 . A capacidade de armazenamento de água com o índice de abstração inicial do simulador de chuva foi superior a todos os outros armazenamentos encontrados para a simulação do café - primavera-verão, com média de 494,83 mm. Como mencionado nas simulações anteriores, para a cultura do café, o valor CNtb na condição antecedente de umidade II, grupo hidrológico do solo ' $\mathrm{C}$ ' foi igual a 72 , valor $\mathrm{CN} 8$ pontos inferiores ao CNsi e 17 pontos superior ao CNp-q.

No entanto, essa simulação do período primavera-verão foi enquadrada na condição antecedente de umidade III, e o valor CNtb eleva-se de 72 para 86, o que faz do CNsi 6 pontos inferiores ao $\mathrm{CNtb}$, e faz do $\mathrm{CNp}$-q, em média, 31 pontos inferiores ao $\mathrm{CNtb}$ - AMC III. A média do valor CNp-q enquadra-se mais no valor CNtb - AMC I que reduz de 86 (AMC III) para 53, muito próximo ao valor CNp-q, que foi em média igual a 55 (variou de 52 a 58). Pode-se inferir que o valor CNsi dessa simulação foi próximo ao valor CNtb nas condições de umidade II e III, e, por outro lado, o valor $\mathrm{CNp}$-q foi igual ao CNtb na condição antecedente de umidade I.

\subsection{Segunda simulação - primavera-verão}

$\mathrm{Na}$ Tabela 4, observam-se os dados da simulação realizada no período primaveraverão. Como mencionado, a segunda simulação da cultura do café foi realizada 30 minutos após o término da primeira simulação. $\mathrm{Na}$ Tabela 4, são apresentados os dados do volume de escoamento superficial, o volume de abstração inicial, o volume de armazenamento de água pelo solo e os respectivos valores $\mathrm{CN}$. Também podem ser verificados os índices de abstração inicial obtidos a partir do volume de abstração inicial correlacionados às capacidades de armazenamento de água pelo solo. 
Tabela 4: Volume de escoamento superficial, de abstração inicial e capacidade de armazenamento de água, valores $\mathrm{CN}$ e índices de abstração inicial - período primavera-verão

\begin{tabular}{|c|c|c|c|c|c|c|c|c|c|}
\hline CALHAS & $\mathrm{Q}(\mathrm{mm})$ & $\mathrm{la}(\mathrm{mm})$ & $\mathrm{Ssi}(\mathrm{mm})$ & $\mathrm{CNsi}$ & $\lambda \mathrm{si}$ & $\mathrm{Sp}-\mathrm{q}(\mathrm{mm})$ & $\lambda p-q$ & $\mathrm{CNp}-\mathrm{q}$ & $\mathrm{S} \lambda(\mathrm{mm})$ \\
\hline 4A & 1,63 & 4,06 & 64,88 & 80 & 0,06 & 231,32 & 0,02 & 52 & 564,39 \\
\hline 4B & 1,96 & 4,62 & 64,55 & 80 & 0,07 & 223,02 & 0,02 & 53 & 484,84 \\
\hline 4C & 6,26 & 1,85 & 60,25 & 81 & 0,03 & 158,60 & 0,01 & 62 & 410,58 \\
\hline 4D & 3,51 & 3,14 & 63,00 & 80 & 0,05 & 193,27 & 0,02 & 57 & 477,25 \\
\hline MÉDIA & 3,34 & 3,42 & 63,17 & 80 & 0,05 & 201,55 & 0,02 & 56 & 484,27 \\
\hline
\end{tabular}

Q - escoamento superficial; la - abstração inicial; Ssi - capacidade de armazenamento de água do solo; $\lambda$ si - índice de la/Ssi; CNsi - valor CN; Sp-q - capacidade de armazenamento de água do solo com la $=0,2 ; \lambda p-q$ - índice de la/Sp-q; CNp-q - valor $\mathrm{CN}$; $\mathrm{S} \lambda$ - capacidade de armazenamento de água do solo com relação ao $\lambda$ si.

Para a segunda simulação, no período primavera-verão, observa-se em média um maior volume de escoamento superficial (média de 3,34 $\mathrm{mm}$ ) se comparado com a primeira, e uma variação de $1,63 \mathrm{~mm}$ a $6,26 \mathrm{~mm}$. A calha 4C (volume de $6,26 \mathrm{~mm}$ ) apresentou o maior volume de escoamento superficial entre todas as simulações realizadas na cultura do café, fato que, como mencionado, pode ser atribuído pelo direcionamento do fluxo d'água pelos galhos da planta de uma parcela para a outra, situação semelhante ao que pode ocorrer em áreas de matas, devido ao escoamento pelo tronco.

Como a abstração inicial foi determinada pelo início do escoamento superficial, temos na calha $4 \mathrm{C}$ o menor volume de abstração inicial, pois nela o início do escoamento superficial ocorreu primeiro do que nas outras calhas para esta simulação. Entretanto, houve uma considerável variação no volume de abstração inicial, de $1,85 \mathrm{~mm}$ a 4,62 $\mathrm{mm}$, e uma média de $3,42 \mathrm{~mm}$.

No geral, como o volume de escoamento superficial foi maior do que na primeira simulação do período, o volume de armazenamento foi menor, variando de $60,25 \mathrm{~mm}$ a $64,88 \mathrm{~mm}$, com média de $63,17 \mathrm{~mm}$. Como a calha $4 \mathrm{C}$ apresentou o maior volume de escoamento superficial, houve uma elevação do valor CNsi para 81, mas a média entre todas as calhas permaneceu em $\mathrm{CNsi}=80$, e a média do índice de abstração inicial do simulador de chuva foi $\lambda s i=0,05$, inferior ao determinado pelo $\operatorname{NRCS}(\lambda=0,2)$, com variação de 0,03 a 0,07 . O armazenamento de água, que considera a la=0,2 $S$, variou de $158,60 \mathrm{~mm}$ a $231,32 \mathrm{~mm}$, produzindo, consequentemente, um menor índice de abstração inicial, oscilando de 0,01 a 0,02 e média de 0,02.

Como o armazenamento de água do solo com la=0,2.S é maior do que o armazenamento do simulador de chuva, o valor $\mathrm{CNp}$-q foi menor do que o valor $\mathrm{CNsi}$, variando de 52 a 62 e média de 56. Assim, da mesma forma como na primeira simulação do período, os valores CNsi foram mais próximos de CNtb na condição antecedente de umidade III, e o valor $\mathrm{CNp}$-q foi mais próximo ao valor $\mathrm{CNtb}$ na condição antecedente de umidade I.

A capacidade de armazenamento de água do solo com o índice de abstração inicial do simulador de chuva foi mais do que o dobro do armazenamento com $\lambda=0,2$, o que, consequentemente, reduz, consideravelmente, o valor $\mathrm{CN}$ obtido com esse volume de 
armazenamento. O índice de abstração inicial do simulador de chuva ( $\lambda$ si) para as simulações no período primavera-verão foram menores do que o índice de la do simulador de chuva do período outono-inverno, provavelmente devido à maior umidade do solo nesse período, o que está de acordo com a AMC III, e este ser o período de chuvas para a região.

Todos os índices de abstração inicial obtidos nessa simulação foram inferiores ao determinado oficialmente pelo NRCS, e o valor CNsi foi inferior ao CNtb - AMC III selecionados nas tabelas do NRCS e superior ao valor CNtb - AMC II. Como pode ser observado na Tabela 4, o valor CNsi médio foi de 80 , inferior ao CNtb=86 (AMC III), indicando uma melhor capacidade de armazenamento de água do solo do uso da terra café no período primavera-verão do que mostra o valor $\mathrm{CNtb}$. Um simples valor CN pode não indicar as características da bacia hidrográfica devido à variação na textura do solo, variações na declividade, umidade, usos da terra e cobertura do solo.

No período outono-inverno, tem-se na primeira e na segunda simulação uma média do índice de la $\lambda=0,14$ e $\lambda=0,13$ respectivamente, e para o período primavera-verão com $\lambda=0,06$ e $\lambda=0,05$ para a primeira e para a segunda simulação, respectivamente. Isso pode indicar não ser seguro adotar um único índice de abstração inicial para as diversas estações do ano nas condições climáticas de uso e de ocupação da terra e do tipo de solo verificadas na pesquisa. Como nas outras simulações no uso da terra café, o índice de abstração inicial foi inferior ao adotado pelo método SCS-CN.

De acordo com do Valle Junior, Rodrigues e de Oliveira (2019), foram determinados os valores $\mathrm{CN}$ e os índices de abstração inicial em uma bacia hidrográfica rural no Estado de Mato Grosso do Sul a partir de dados de precipitação e de escoamento superficial, com o objetivo de avaliar o desempenho do Método CN em uma bacia hidrográfica rural tropical. Os índices de abstração inicial variaram de 0,005 a 0,455, recomendando o índice de 0,05 ao invés de 0,2 para bacias hidrográficas semelhantes à estudada. Observa-se que os índices de abstração inicial recomendados em clima tropical úmido com inverno seco e verão quente-chuvoso, com predomínio de pastagens no grupo hidrológico do solo $\mathrm{A}$ e $\mathrm{B}$, foram próximos aos da abstração inicial do simulador de chuva $(\lambda \mathrm{si})$ na cultura café do período primavera-verão com média de $\lambda s i=0,06\left(1^{\circ}\right.$ simulação) e $\lambda s i=0,05$ ( $2^{\circ}$ simulação).

Os valores CN obtidos no uso da terra café com a utilização do simulador de chuvas foram comparados aos valores CN na cultura do café em Porto Rico. Os dados foram obtidos em Mayagüez (Porto Rico), onde o clima predominante é o tropical de monções com temperatura média anual de $24^{\circ} \mathrm{C}$, com inverno seco e frio, com verão quente e úmido (USDA-NRCS, 2004b). O valor CN no uso da terra café para Porto Rico subdivide-se em áreas de café sem cobertura do solo e sem terraços, e áreas com cobertura do solo e com terraços. Nesse sentido, considerando-se a cobertura vegetal e os terraços presentes na área do experimento, grupo hidrológico do solo "C", o valor CN-AMC II é 68, AMC I=48 e AMC III=84.

Comparando-se os valores $\mathrm{CN}$ de Porto Rico na cultura do café com os valores $\mathrm{CN}$ do experimento do simulador no café, o valor CNsi médio igual a 80 da primeira 
simulação da primavera-verão ficou entre os valores CN-Porto Rico nas condições antecedentes de umidade II e III. Já o valor CNp-q médio $(\mathrm{CNp}-\mathrm{q}=56)$ ficou entre os valores CN-Porto Rico na condição antecedente de umidade I ( $\mathrm{CN}=48)$ e II ( $\mathrm{CN}=68)$. Os resultados das capacidades de armazenamento de água do solo (S) e os seus respectivos valores $\mathrm{CN}$ evidenciam que quanto maiores os índices de abstração inicial utilizados para determinar os valores $\mathrm{CN}$, menores serão os valores $\mathrm{CN}$ e vice-versa, e que um único valor $\mathrm{CN}$ pode não representar períodos de chuva prolongados nas condições edafoclimáticas da pesquisa.

Os índices de abstração inicial do simulador de chuva $(\lambda s i)$ do período outono-inverno foram maiores do que os da primavera-verão, devido ao menor volume de precipitação. Os valores $\mathrm{CNsi}$ do outono-inverno foram próximos aos valores $\mathrm{CN}$ Porto Rico na condição antecedente de umidade III $(\mathrm{CN}=84)$ no café em Porto Rico. Segundo Elhakeem e Papanicolaou (2009), os dados obtidos em campo (parcelas experimentais) de bacias hidrográficas podem compor outros dados para representar uma determinada bacia hidrográfica. Pesquisa conduzida no semiárido sudoeste dos EUA, na Bacia Hidrográfica Experimental do Walnut Gulch (Arizona), produziu valores $\mathrm{CN}$ por meio de três diferentes formas. A área de estudo onde foi realizado o experimento possuía parcelas cobertas por gramíneas, grupo hidrológico 'B' com 8$15 \%$ de declividade. Outras parcelas cobertas por arbustos (30 a 40\%), classificadas como pastagens ruins no grupo hidrológico ' $\mathrm{C}$ ' com $3 \%$ a $8 \%$ de declividade.

Ainda de acordo com Elhakeem e Papanicolaou (2009), valores CN selecionados nas tabelas do NEH-4 determinam menores volumes de escoamento superficial do que aqueles realmente verificados em algumas bacias hidrográficas do oeste dos EUA, visto que o método SCS-CN teve sua grande base em dados produzidos na região leste. A porcentagem de cobertura vegetal interfere no valor $\mathrm{CN}$, ou seja, quanto maior a porcentagem de cobertura vegetal menor será o valor $\mathrm{CN}$. Com os experimentos, concluiu-se que os valores CN obtidos a partir de dados de precipitação e de escoamento superficial em parcelas experimentais podem ser mais altos que os valores $\mathrm{CN}$ selecionados nas tabelas do $\mathrm{NEH}-4$. Esse fato foi atribuído à falta de rugosidades das parcelas se comparado ao relevo de uma bacia hidrográfica, rugosidade essa responsável por 'abstrações' da precipitação e, consequentemente, redução do escoamento superficial.

Valores $\mathrm{CN}$ alcançados em áreas maiores do que em parcelas experimentais, mas com complexos de cobertura do solo semelhantes, apresentam menores valores $\mathrm{CN}$ do que em parcelas experimentais. Esses altos valores $\mathrm{CN}$ verificados nas parcelas experimentais podem ser atribuídos a elevado volume precipitado e escoado produzido a partir de uma chuva natural em uma parcela experimental, principalmente em regiões como no estado do Arizona (Elhakeem, Papanicolaou, 2009).

Conforme Elhakeem e Papanicolaou (2009), na produção de valores CN em bacias hidrográficas semelhantes às encontradas na região sudeste do Arizona, alguns fatores são fundamentais, a saber: a intensidade da chuva, o complexo solo-cobertura vegetal e a condição antecedente de umidade. No entanto, salienta-se que a condição 
antecedente de umidade definida pelo NEH-4 (AMC) é insuficiente para representar todas as condições de umidade que podem ser encontradas no sudeste semiárido do Arizona, situação semelhante às que poderiam ser encontradas no nordeste brasileiro. Recomenda-se a criação de mais condições antecedentes de umidade (AMC), ou até mesmo outras classes para representar a AMC, além da condição antecedente de umidade I, II e III existentes no Método SCS-CN. Atualmente, o NRCS transformou a condição antecedente de umidade em condição antecedente de escoamento superficial (ARC).

Conforme Lal et al. (2016), uma pesquisa conduzida no território indiano produziu valores $\mathrm{CN}$ para diversos usos da terra agrícola, como cana-de-açúcar, milho, feijão e áreas em pousio por meio da utilização de parcelas experimentais de $22 \mathrm{~m} \times 5 \mathrm{~m}$. Os usos da terra analisados nas parcelas experimentais não apresentaram diferenças significativas nos valores $\mathrm{CN}$, com exceção de alguns usos com menores valores $\mathrm{CN}$ do que a cana-de-açúcar, como parcela com o feijão e a parcela em pousio. No uso da terra café até mesmo precipitações realizadas em sequência (no mesmo dia) não apresentaram mudanças significativas nos valores CNsi. Entretanto, chuvas volumosas produzem menores valores $\mathrm{CN}$ do que precipitações de menor volume, tanto considerando o valor $\mathrm{CNsi}$, CNp-q ou $\mathrm{CN} \lambda$.

Verificou-se que para o uso da terra café, as simulações de 30 minutos apresentaram média do valor CNsi (89) maior do que o valor CNtb na condição de umidade III $(\mathrm{CNtb}=86)$ e o valor CNsi médio (80) para simulações de 60 minutos ficaram entre 0 CNtb-AMC II (72) e AMC III (86) e distantes da condição antecedente de umidade I (53). Segundo Lal et al. (2016), o valor CN obtido nas tabelas do NEH-4 foram comparados com os valores coletados a partir de dados naturais e ordenados de precipitação e de escoamento superficial observados nas parcelas experimentais. Os valores $\mathrm{CN}$ alcançados no NEH-4 variaram de 58 a 88. Com o método dos mínimos quadrados para os dados naturais, os valores $\mathrm{CN}$ variaram de 64,73 a 90,33, e para os dados ordenados 67,47 para 90,59. Em suma, os valores $C N$ com dados ' $P-Q$ ' foram maiores que os do NEH-4.

Segundo Lal et al. (2016), há um melhor desempenho do Método SCS-CN quando analisados os eventos ' $P$ - $Q$ ' elevados ou $C N$ elevados. Os valores $C N$ ordenados são maiores do que os $\mathrm{CN}$ naturais. Os autores indicam a utilização do $\mathrm{CN}$ ordenado ao invés do $\mathrm{CN}$ obtido nas tabelas do $\mathrm{NEH}-4$ para áreas com características físicas semelhantes ao das parcelas experimentais.

No artigo apresentado por Hawkins (1978), foram determinados o escoamento superficial e o valor $\mathrm{CN}$ por meio de dados de precipitação e taxas de perdas (infiltração) em parcelas experimentais. Para isso, utilizaram a Equação Geral do Método $\mathrm{CN}$ e uma fórmula para determinar o armazenamento de água do solo considerando dados de precipitação e de escoamento superficial. Os valores de escoamento superficial com a Equação Geral foram maiores do que o escoamento superficial obtido pela fórmula que considera dados de precipitação e de escoamento. Por sua vez, os valores CN encontrados com a Equação Geral foram superiores aos 
obtidos com os dados P-Q. Portanto, a utilização da Equação Geral com la=0,2.S leva a uma superestimava do escoamento superficial. Sugere-se que a fórmula funcione como uma alternativa à Equação Geral do Método $\mathrm{CN}$ e, possivelmente, com resultados mais confiáveis.

Valores CN foram determinados a partir de dados de precipitação e de escoamento superficial coletados a partir de duas bacias hidrográficas florestadas na Carolina do Sul (EUA). Os valores CN variaram de 46 a 90 para uma das bacias hidrográficas e de 42 a 89 para a outra. Nesta pesquisa, a formação do escoamento superficial foi relacionada à elevação do nível do lençol freático, onde sazonalmente há variações entre períodos úmidos e períodos secos (Epps et al., 2013). O NRCS recomenda a utilização do termo 'condição antecedente de escoamento' em substituição a 'condição antecedente de umidade'. Epps et al. (2013) recomendam a definição da condição antecedente de escoamento em função do nível do lençol freático para o ajuste dos valores $\mathrm{CN}$, melhorando a estimativa do escoamento superficial.

Epps et al. (2013) ressaltam a necessidade de adaptações dos parâmetros utilizados pelo Método SCS-CN para predição do fluxo para as bacias hidrográficas analisadas na Carolina do Sul, devendo, para isto, considerar as variações no nível do lençol freático. Quanto maior foi o nível do lençol freático, maiores foram os valores $\mathrm{CN}$ e, em épocas em que o nível do lençol freático se encontrava baixo, menores foram os valores $\mathrm{CN}$ encontrados. Ainda nesse sentido, a precipitação acumulada nos cinco dias anteriores ao evento mostrou-se correlata, pois quanto menor foi a precipitação acumulada menores foram os valores $\mathrm{CN}$.

De acordo com Ajmal et al. (2015), os valores CN calibrados a partir de dados de precipitação e de escoamento superficial captados em bacias hidrográficas regionais reduzem erros na estimativa do escoamento superficial. Mishra et al. (2014) investigaram os efeitos da declividade nas bacias hidrográficas na formação do escoamento superficial e no próprio valor $\mathrm{CN}$ em parcelas experimentais de dimensão $22 \mathrm{~m}$ x $5 \mathrm{~m}$ nos usos da terra milho e cana-de-açúcar, com grupo hidrológico do solo C na Índia.

Os resultados evidenciaram o efeito da declividade na formação do escoamento superficial e no valor $\mathrm{CN}$, onde o declive de $5 \%$ produziu maior valor $\mathrm{CN}$ (maior escoamento superficial) do que se comparado com parcelas com $1 \%$ e $3 \%$ para um mesmo grupo hidrológico do solo e uso da terra. Para um mesmo uso da terra, o escoamento superficial aumenta à medida que a declividade aumenta. De acordo com Mishra et al. (2014), os valores CN obtidos a partir das parcelas experimentais foram próximos aos valores $\mathrm{CN}$ das tabelas do NRCS. Como o valor $\mathrm{CN}$ aumenta de AMC I para o AMC III, os valores $\mathrm{CN}$ se elevam conforme aumenta o declive para um mesmo uso da terra.

\section{Conclusões}

A utilização do simulador de chuvas com o intuito de replicar eventos naturais de forma artificial se mostrou positiva, visto que a utilização do equipamento forneceu ambiente 
propício para avaliação e coleta de dados necessários para alimentar o modelo, de maneira a contemplar as necessidades específicas da pesquisa, como: capacidade de utilização em campo; replicar precipitações de forma ininterrupta nos tempos necessários; produzir cobertura homogênea de forma simultânea em 4 parcelas de $1 \mathrm{~m}^{2}$; gerar precipitações homogêneas em diferentes estações do ano, passiveis de comparação entre as mesmas.

Apesar de simuladas chuvas de forma consecutiva sobre a cultura do café, os valores de abstração inicial se mostraram próximos entre as simulações do mesmo dia e entre estações, sendo para outono/inverno valores de $4,43 \mathrm{~mm}$ na primeira simulação, 4,25 $\mathrm{mm}$ para segunda e primavera/verão 3,76 $\mathrm{mm}$ e 3,42 $\mathrm{mm}$ respectivamente.

Para o período outono/inverno, o índice de abstração inicial do simulador de chuva $(\lambda s i)$ apresentou valores ligeiramente menores em relação aos adotados pela metodologia SCS-CN, 0,14 e 0,2 respectivamente. Todavia, o índice de abstração inicial com Sp-q apresentou-se três vezes menor que $\lambda$ si. Para o período primavera/verão, os valores encontrados se mostram bem próximos quando comparados ao outono/inverno, apresentando abstração inicial um pouco menor e volumes escoados ligeiramente maiores.

No geral, todos os índices de abstração inicial coletados neste trabalho por meio de simulações de chuva foram inferiores ao determinado oficialmente pelo NRCS. Observou-se que quanto menor o índice de abstração inicial utilizado para a determinação do valor $\mathrm{CN}$, por meio de fórmulas que consideram dados de precipitação e de escoamento superficial, maiores foram os valores $\mathrm{CN}$, e que os valores $\mathrm{CNp}$-q foram menores do que os valores $\mathrm{CNsi}$, influenciados pelo índice de abstração inicial $\lambda=0,2$.

Verificou-se a interferência do volume de precipitação nas capacidades de armazenamento de água do solo e nos respectivos valores $\mathrm{CN}$. O valor CNsi médio do período outono-inverno ficou próximo aos valores CNtb dos EUA e de Porto Rico na condição antecedente de umidade III, considerando as duas simulações realizadas então. Por sua vez, no período primavera-verão, o valor CNsi ficou entre as condições antecedentes de umidade II e III, tanto para os valores CNtb do território dos EUA e para o CNtb do café em Porto Rico, demonstrando a real necessidade de aquisição de dados locais para melhor funcionamento e veracidade dos dados expostos pelo uso do modelo.

Os tempos de resposta assim como os baixos valores de escoamento superficial estão intimamente ligados à estrutura vegetativa da planta de café, visto que seu porte arbustivo e densidade de galhos e folhas auxiliam na redistribuição e na retenção interna dos fluxos de água, de forma a armazenar parte do volume precipitado sobre sua superfície interna e externa (tronco e folhas), reduzindo o impacto das gotas diretamente sobre o solo e conservando sua estrutura. O manejo de alocar as folhas caídas da cultura sob as plantas de café também auxiliou na retenção de água, de forma a produzir um ambiente com capacidade de interceptar e reter fluxos, 
promovendo rugosidades na superfície, desacelerando o escoamento e permitindo a infiltração de maiores volumes no solo.

Verificou-se que mesmo realizando simulações em intervalos de horas não houve grandes alterações dos valores $\mathrm{CN}$, indicando uma constante nas características hidrológicas que as linhas do café apresentam. Todavia, deve-se considerar que o experimento foi realizado nas linhas do café com plantas bastante desenvolvidas. Ainda sob essa ótica, pode-se observar uma estabilidade nos valores CNsi médios derivados de simulações com 10 minutos de duração e nas simulações com 60 minutos de duração no Cerrado, evidenciando a redução do valor CNsi médio com o aumento do volume de precipitação que, no caso, coincide com a simulação de maior duração.

A variação do volume de abstração inicial entre as calhas das simulações do período primavera-verão ficou entre $1,85 \mathrm{~mm}$ e $4,9 \mathrm{~mm}$, variações semelhantes às que podem ser encontradas em fitofisionomias como as do cerrado, no qual o escoamento pelo tronco pode interferir no fluxo d'água até a infiltração, justificando a variação do volume de abstração entre as calhas.

Nas calhas que apresentaram maior escoamento superficial foi onde observou-se o menor volume de abstração inicial, o que, por sua vez, apresentou o menor índice de abstração inicial do simulador de chuva $(\lambda s i=0,03)$. Quanto maior o armazenamento de água do solo maior foram os volumes de abstração inicial. As variações dos dados entre as calhas também foram verificadas no escoamento superficial, no armazenamento de água do solo e também nos índices de abstração inicial. Concluise que para utilização de modelos preditivos, necessita-se da calibração de algumas variáveis, como as características da vegetação, abstração inicial, tipo de solo, umidade antecedente e produção de fluxos superficiais, visto que são incorporadas de ambientes que possuem características edafoclimáticas distintas de outras regiões que possam vir a ser utilizados.

\section{Agradecimentos}

Agradecemos ao Programa de Pós-Graduação em Geografia da Universidade Federal de Uberlândia (PPGEO-UFU). Agradecemos a todos os funcionários e aos professores do Campus Experimental do Glória. Agradecemos à CAPES projeto DINTER UFU-IFG pela bolsa de doutorado, e agradecemos à CAPES pela bolsa de mestrado (PPGEO-UFU).

\section{Financiamento}

Bolsa de doutorado e de mestrado financiadas pela Coordenação de Aperfeiçoamento de Pessoal de Nível Superior (CAPES).

\section{Disponibilidade dos Dados científicos}

Dados publicados em Carvalho (2018) e Confessor (2019). 


\section{Bibliografia}

Ajmal, M., Moon, G., Ahn, J., Kim, T. (2015). Investigation of SCS-CN and its inspired modified models for runoff estimation in South Korean watersheds. Journal of Hydro-Environment Research, 9, 592-603. https://doi.org/10.1016/j.jher.2014.11.003

Baltas, E. A., Dervos, N. A., Mimikou, M. A. (2007). Technical Note: Determination of the SCS initial abstraction ratio in an experimental watershed in Greece. Hydrol. Earth Syst. Sci, 11, 1825-1829. https://doi.org/10.5194/hess-11-1825-2007

Bastos, F. R., Melo, B. de (2008). Avaliação de linhagens da cultivar de cafeeiro topázio nas condições do município de Uberlândia - MG. In VIII Encontro Interno - XII Seminário de Iniciação Científica. (pp. 1-2). Disponível em: http://www.sbicafe.ufv.br/bitstream/handle/123456789/6331/doc 103 34-CBPC2008.pdf? sequence $=1$ \&isAllowed $=y$

Carvalho, F. (2018). Abstração inicial e valores CN em diferentes usos da terra no cerrado com utilização de um simulador de chuva. Tese de doutoramento, Universidade Federal de Uberlândia. Disponível em: https://repositorio.ufu.br/bitstream/123456789/24429/1/AbstraçãoinicialvaloresCN.pdf

Confessor, J. G. (2019). Avaliação de processos erosivos hídricos em diferentes usos agrícolas, utilizando simulador de chuvas no ambiente de Cerrado. Dissertação de mestrado, Universidade Federal de Uberlândia. Disponível em: https://repositorio.ufu.br/bitstream/123456789/24312/1/AvaliacaoProcessosErosivos.pdf

Confessor, J. G., Rodrigues, S. C. (2018). Método para calibração, validação e utilização de simuladores de chuvas aplicados a estudos hidrogeomorfológicos em parcelas de erosão. Revista Brasileira de Geomorfologia, 19(1), 221-229. http://dx.doi.org/10.20502/rbg.v19i1.1294

D'Asaro, F., Grillone, G. (2012). Empirical investigation of Curve Number Method parameters in the mediterranean area. Journal of Hydrologic Engineering, 17(10), 1141-1152. https://doi.org/10.1061/(ASCE)HE.1943-5584.0000570

D'Asaro, F., Grillone, G. (2015). Discussion: Curve Number Derivation for Watersheds Draining Two Headwater Streams in Lower Coastal Plain South Carolina, USA. JAWRA Journal of the American Water Resources Association, 51(2), 573-578. https://doi.org/10.1111/jawr.12264

D’Asaro, F., Grillone, G. (2010). Runoff Curve Number Method in Sicily: CN determination and analysis of the initial abstraction ratio. 2nd Joint Federal Interagency Conference, June, 112. Disponível em: https://acwi.gov/sos/pubs/2ndJFIC/Contents/11E D'Asaro Grillone.pdf

da Silva, C. A., Teodoro, R. E. F., de Melo, B. (2008). Produtividade e rendimento do cafeeiro submetido a lâminas de irrigação. Pesquisa Agropecuaria Brasileira, 43(3), 387-394. https://doi.org/10.1590/S0100-204X2008000300014

do Valle Junior, L. C. G., Rodrigues, D. B. B., de Oliveira, P. T. S. (2019). Initial abstraction ratio and Curve Number estimation using rainfall and runoff data from a tropical watershed. Revista Brasileira de Recursos Hidricos, 24, 1-9. https://doi.org/10.1590/2318$\underline{0331.241920170199}$ 
Elhakeem, M., Papanicolaou, A. N. (2009). Estimation of the Runoff Curve Number via direct rainfall simulator measurements in the state of lowa, USA. Water Resources Management, 23, 2455-2473. https://doi.org/10.1007/s11269-008-9390-1

EMBRAPA (1997). Manual de Métodos de Análise de Solo. Embrapa. Centro Nacional de Pesquisa de Solos.

Epps, T. H., Hitchcock, D. R., Jayakaran, A. D., Loflin, D. R., Williams, T. M., Amatya, D. M. (2013). Curve number derivation for watersheds draining two headwater streams in lower coastal plain south carolina, USA. Journal of the American Water Resources Association, 49, 1284-1295. https://doi.org/10.1111/jawr.12084

Hawkins, R. H. (1978). Effects of rainfall intensity on runoff curve numbers. Hydrology and Water Resources in Arizona and the Southwest, 8, 53-64.

Hawkins, R. H., Ward, T. J., Woodward, D. E., Mullem, J. A. Van (Eds.). (2009). Curve Number Hydrology - State of the Practice. ASCE/EWRI - Environmental and Water Resources Institute (EWRI) of the American Society of Civil Engineers.

Jiang, R. (2001). Investigation of Runoff Curve Number Initial Abstraction Ratio. Tese de mestrado, School of Renewable Natural Resources. http://arizona.openrepository.com/arizona/handle/10150/191301

Lal, M., Mishra, S. K., Pandey, A., Pandey, R. P., Meena, P. K., Chaudhary, A., Jha, R. K., Shreevastava, A. K., Kumar, Y. (2016). Evaluation of the Soil Conservation Service curve number methodology using data from agricultural plots. Hydrogeology Journal, 1-17. https://doi.org/10.1007/s10040-016-1460-5

Luk, S., Abrahams, A. D., Parsons, A. J. (1986). Methodology: A simple rainfall simulator and trickle system for hydro-geomorphological experiments. Physical Geography, 7, 344-356. https://doi.org/10.1080/02723646.1986.10642303

Mello, C. R. de, Lima, J. M. de, Silva, A. M. da, Lopes, D. (2003). Abstração inicial da precipitação em microbacia hidrográfica com escoamento efêmero. Revista Brasileira de Engenharia Agrícola e Ambiental, 7, 494-500. https://doi.org/10.1590/S1415$\underline{43662003000300015}$

Mishra, S. K., Chaudhary, A., Shrestha, R. K., Pandey, A., Lal, M. (2014). Experimental verification of the effect of slope and land use on SCS Runoff Curve Number. Water Resources Management, 28, 3407-3416. https://doi.org/10.1007/s11269-014-0582-6

Silveira, A. L. L. (2009). Ciclo hidrológico e bacia hidrográfica. In Carlos E. M. Tucci (Ed.), Hidrologia: Ciência e aplicação (Tucci, Car, pp. 35-52). Editora da UFRGS/ ABRH.

Tucci, C. E. M. (2009a). Controle de enchentes. In C. E. M. TUCCI (Ed.), Hidrologia: Ciência e aplicação (4th ed., pp. 621-658). Editora da UFRGS/ ABRH.

Tucci, C. E. M. (2009b). Hidrologia: Ciência e aplicação. In C. E. M. TUCCI (Ed.), Hidrologia: Ciência e aplicação (4th ed., pp. 25-34). Editora da UFRGS/ ABRH.

USDA-NRCS (1986). TR-55 - Urban Hydrology for Small Watersheds. Technical Release 55. Natural Resources Conservation Service.

USDA-NRCS (2002). Land Use and Treatment Classes. In Part 630 Hydrology National Engineering Handbook. Natural Resources Conservation Service. Disponível em: http://www.wcc.nrcs.usda.gov/ftpref/wntsc/H\&H/NEHhydrology/ch8.pdf 
USDA-NRCS. (2004a). Estimation of direct runoff from storm rainfall. In Part 630 Hydrology National Engineering Handbook. Natural Resources Conservation Service. Disponível em: http://www.wcc.nrcs.usda.gov/ftpref/wntsc/H\&H/NEHhydrology/ch10.pdf

USDA-NRCS (2004b). Hydrologic Soil-Cover Complexes. In Part 630 Hydrology National Engineering Handbook. United States Department of Agriculture - Natural Resources Conservation

Service.

Disponível

em:

http://www.wcc.nrcs.usda.gov/ftpref/wntsc/H\&H/NEHhydrology/ch9.pdf

USDA-NRCS (2009). Hydrologic Soil Groups. In Part 630 Hydrology National Engineering Handbook. Natural Resources Conservation Service. Disponível em: http://www.wcc.nrcs.usda.gov/ftpref/wntsc/H\&H/NEHhydrology/ch7.pdf

Woodward, D. E., Hawkins, R. H., Hjelmfelt Jr., A. T., Van Mullem, J. A., Quan, Q. D. (2002). Curve number method: Origins, applications and limitations. Disponível em: https://www.wcc.nrcs.usda.gov/ftpref/wntsc/H\&H/CNarchive/CNorigins.doc

Artigo recebido em / Received on: 30/10/2020

Artigo aceite para publicação em / Accepted for publication on: 30/12/2020 